\title{
CONTROLE QUÍMICO DA LAGARTA-ENROLADEIRA (BONAGOTA CRANAODES MEYRICK) NA CULTURA DA MACIEIRA ${ }^{1}$
}

\author{
MARCOS BOTTON² OCTÁVIO NAKANO $^{3}$ e ADALÉCIO KOVALESKI²
}

\begin{abstract}
RESUMO - A lagarta-enroladeira, Bonagota cranaodes Meyrick (Lepidoptera: Tortricidae), é considerada uma das principais pragas da macieira no Brasil. Com o objetivo de selecionar inseticidas visando ao controle do inseto, experimentos de laboratório e campo foram conduzidos com clorpirifósetil (Lorsban $480 \mathrm{CE}-72 \mathrm{~g}$ de i.a./100 L), metidatiom (Supracid 400 - $60 \mathrm{~g}$ de i.a/100 L), fosmet (Imidan 50 PM - $100 \mathrm{~g}$ de i.a./100 L), triclorfom (Dipterex 500 - $150 \mathrm{~g}$ de i.a./100 L), tebufenozide (Mimic 240 SC - 21,6 g de i.a./100 L), fenitrotiom (Sumithion 500 CE - 75 g de i.a./100 L) e carbaril (Sevin 850 PM - 153 g de i.a./100 L). Todos os inseticidas provocaram $100 \%$ de mortalidade de lagartas recém-eclodidas em laboratório, porém, o controle de lagartas de $4^{\circ}$ e $5^{\circ}$ ínstar, após seu estabelecimento nas plantas de macieira, somente foi satisfatório com clorpirifós-etil, tebufenozide e triclorfom. A pulverização de clorpirifós-etil, após picos de captura dos machos de B. cranaodes com armadilhas de feromônio sexual resultaram em menos de $1 \%$ de frutos danificados na colheita em comparação com $4,6 \%$ com tebufenozide, e $9,8 \%$ na testemunha.
\end{abstract}

Termos para indexação: insetos, armadilhas sexuais, controle de insetos, inseticidas, métodos de aplicação.

\author{
CHEMICAL CONTROL OF APPLE LEAFROLLER \\ (BONAGOTA CRANAODES MEYRICK) IN APPLE ORCHARDS
}

\begin{abstract}
Apple leafroller, Bonagota cranaodes Meyrick (Lepidoptera: Tortricidae), is one of the major apple pests in Southern Brazil. Laboratory and field experiments were conducted with chlorpyriphos-ethyl (Lorsban $480 \mathrm{CE}$ - $72 \mathrm{~g}$ of a.i./100 L), methidathion (Supracid 400 - $60 \mathrm{~g}$ of a.i./100 L), phosmet (Imidan $50 \mathrm{PM}-100 \mathrm{~g}$ of a.i./100 L), trichlorphon (Dipterex $500-150 \mathrm{~g}$ of a.i./100 L), tebufenozide (Mimic $240 \mathrm{SC}-21.6 \mathrm{~g}$ of a.i./100 L), fenitrothion (Sumithion $500 \mathrm{CE}-75 \mathrm{~g}$ of a.i./100 L) and carbaryl (Sevin $850 \mathrm{PM}-153 \mathrm{~g}$ of a.i./100 L) to control the pest in apple orchards. In laboratory, all insecticides caused $100 \%$ of mortality on first-instars larvae while fourth and fifth instar larvae were satisfactorily controlled only using chlorpyriphos-ethyl, tebufenozide and trichlorphon. Chlorpyriphosethyl application after peaks of $B$. cranaodes males capture in pheromone traps resulted in less than $1 \%$ of fruit damage at harvest, while tebufenozide resulted in $4.6 \%$ compared to $9.8 \%$ in a non-treated area.
\end{abstract}

Index terms: insecta, pheromone traps, insect control, insecticides, application methods.

\section{INTRODUÇÃO}

A lagarta-enroladeira, Bonagota cranaodes Meyrick (Lepidoptera: Tortricidae), anteriormente

\footnotetext{
${ }^{1}$ Aceito para publicação em 19 de janeiro de 2000.

${ }^{2}$ Eng. Agrôn., Dr., Embrapa-Centro Nacional de Pesquisa de Uva e Vinho, Caixa Postal 130, CEP 95700-000 Bento Gonçalves, RS. E-mail: marcos@cnpuv.embrapa.br

${ }^{3}$ Eng. Agrôn., Dr., Dep. de Entomologia, ESALQ, Caixa Postal 9, CEP 13418-900 Piracicaba, SP. E-mail: onakano@carpa.ciagri.usp.br
}

conhecida como Phtheochroa cranaodes, é uma das mais recentes pragas da macieira no Brasil (Kovaleski et al.,1998). As primeiras infestações foram relatadas na década de 80 (Lorenzato, 1984), sendo que no ciclo 1984/85 verificou-se o primeiro ataque com prejuízos comerciais, principalmente sobre a cultivar Fuji cuja produção é mais tardia (Kovaleski, 1994).

$\mathrm{O}$ ataque do inseto ocorre nas folhas e frutos, embora nas folhas não se observem perdas econômicas. Os principais prejuízos são verificados quando as lagartas raspam a epiderme dos frutos, deprecian- 
do-os comercialmente. Nos últimos anos, em Vacaria, RS, o dano provocado pelo inseto tem sido superior ao ocasionado pela mosca-das-frutas, Anastrepha fraterculus (Diptera : Tephritidae), (Kovaleski, 1994). Em pomares infestados com B. cranaodes, mesmo com até oito pulverizações de inseticidas fosforados, danos em frutos de 3\% a 5\% têm sido observados. Considerando a produtividade média dos pomares no Rio Grande do Sul ( 25 t/ha), o dano provocado pela praga representa de 750 a $1.250 \mathrm{~kg} / \mathrm{ha}$ a menos de frutos colhidos para consumo in natura, além do desequilíbrio biológico resultante da aplicação de inseticidas com amplo espectro de ação (Kovaleski et al., 1998).

Estudos sobre o controle químico de $B$. cranaodes foram realizados em laboratório (Lorenzato, 1984; Kovaleski, 1994), sem a confirmação da eficiência dos inseticidas em pomares comerciais. Com base nestes trabalhos, foi verificado que o controle das lagartas exercido pelos inseticidas fosforados é ao redor de $40 \%$ a $50 \%$, mesmo nível atingido pelo Bacillus thuringiensis. Os inseticidas piretróides, embora apresentem um controle superior a $90 \%$ (Lorenzato, 1984; Kovaleski, 1994), normalmente provocam desequilíbrios no pomar, favorecendo o ataque do ácaro-vermelho-europeu, Panonychus ulmi, (Orth et al., 1986).

O objetivo deste trabalho foi avaliar a eficiência de diferentes inseticidas para o controle da lagartaenroladeira na cultura da macieira.

\section{MATERIAL E MÉTODOS}

Os experimentos de seleção de inseticidas para o controle da lagarta-enroladeira foram conduzidos em laboratório e nos campos experimentais da Embrapa-Centro Nacional de Pesquisa de Uva e Vinho e em pomar comercial da Agropecuária Schio, localizados em Vacaria, RS $\left(28^{\circ} 30^{\prime} \mathrm{S} / 50^{\circ} 54^{\prime} \mathrm{W}\right)$ no período de janeiro a abril de 1997.

Os inseticidas avaliados foram: clorpirifós-etil (Lorsban $480 \mathrm{CE}-72 \mathrm{~g}$ de i.a./100 L), metidatiom (Supracid 400 $60 \mathrm{~g}$ de i.a./100 L), fosmet (Imidan 50 PM - $100 \mathrm{~g}$ de i.a./100 L), triclorfom (Dipterex 500 - $150 \mathrm{~g}$ de i.a./100 L), tebufenozide (Mimic $240 \mathrm{SC}-21,6 \mathrm{~g}$ de i.a./100 L), fenitrotiom (Sumithion $500 \mathrm{CE}-75 \mathrm{~g}$ de i.a./100 L) e carbaril (Sevin 850 PM - $153 \mathrm{~g}$ de i.a./100 L), mantendose um tratamento testemunha. No tratamento com tebufenozide, adicionou-se o espalhante adesivo Ag-Ben à calda de pulverização na dosagem de $90 \mathrm{~mL} / 100 \mathrm{~L} \mathrm{de}$ água por recomendação do fabricante. Os insetos foram obtidos de criação artificial, mantida em laboratório conforme metodologia descrita por Parra et al. (1995).

Para avaliar o efeito de inseticidas sobre lagartas recém-eclodidas (12 horas de idade), o experimento foi instalado em janeiro de 1997, em laboratório, na temperatura de $25 \pm 3^{\circ} \mathrm{C}$ e U.R. de $80 \pm 10 \%$. Cada parcela experimental foi composta por um pote de plástico com tampa medindo $2,0 \mathrm{~cm} \times 1,0 \mathrm{~cm}$ de altura e diâmetro, respectivamente, estabelecendo-se dez repetições inteiramente casualizadas. Discos de folhas de macieira $(1 \mathrm{~cm})$ da cultivar Fuji foram obtidos com auxílio de um vasador, e em seguida mergulhados por 30 segundos na calda inseticida. Após o tratamento, os discos foram deixados à sombra por duas horas, para secagem. Em cada pote foram utilizados quatro discos e quatro lagartas. Os discos foram sobrepostos, para reduzir a perda de umidade e proporcionar abrigo, avaliando-se a mortalidade 24 horas após.

$\mathrm{O}$ efeito dos inseticidas sobre lagartas de $4^{0}$ e 5 o ínstar foi avaliado no campo, em fevereiro de 1997, sobre mudas de macieira da cultivar Fuji com um ano de idade e com $1,5 \mathrm{~m}$ de altura, plantadas no espaçamento de $1,5 \mathrm{~m} \times 3,0 \mathrm{~m}$, colocando-se, em cada planta, cinco lagartas sobre os ponteiros. O delineamento experimental foi o inteiramente casualizado, com quatro repetições. Os inseticidas foram aplicados 24 horas após a infestação, pulverizando-se as plantas até o ponto de escorrimento, com auxílio de um pulverizador manual com capacidade para dois litros. A avaliação foi realizada contando-se o número de lagartas vivas presentes nas plantas dois dias após a aplicação dos inseticidas (DAT). As lagartas sobreviventes, em cada repetição, foram colocadas no interior de potes de plástico $(7,0 \mathrm{~cm} \times 5,0 \mathrm{~cm})$, com folhas de macieira do respectivo tratamento, e levadas ao laboratório para contagem do número de insetos vivos aos 5 DAT.

Com relação ao efeito dos inseticidas sobre o dano causado pela lagarta-enroladeira em pomar comercial, o experimento foi instalado na cultivar Fuji que tinha oito anos de idade, e fora plantada no espaçamento de $3,0 \mathrm{~m}$ x $3,5 \mathrm{~m}$ com altura aproximada de $2,5 \mathrm{~m}$ a $3,0 \mathrm{~m}$. O delineamento experimental foi o inteiramente casualizado, com quatro repetições, utilizando-se três plantas por parcela. Os inseticidas foram aplicados com atomizador costal motorizado, num volume de $1,8 \mathrm{~L}$ de calda por planta. As aplicações foram realizadas nos dias 20/1, 10/2 e 3/3/1997, estabelecendo-se um intervalo entre os tratamentos de aproximadamente 21 dias. A avaliação foi realizada colhendo-se todos os frutos da planta central de cada parcela, contando-se o número de frutos danificados pela lagarta-enroladeira. 
Nos experimentos em que foi avaliado o número de lagartas sobreviventes, a porcentagem de controle exercida pelos inseticidas foi obtida pela fórmula de Abbott (1925), considerando-se como eficientes os que provocaram mortalidade superior a $80 \%$. Para análise estatística, o número de lagartas vivas $(\mathrm{x})$ foi transformado para $(\mathrm{x}+0,5)^{1 / 2}$; no experimento em que avaliou-se o dano nos frutos, a porcentagem de maçãs danificadas foi transformada para arc seno $(\% / 100)^{1 / 2}$. Em todos os experimentos, as médias foram comparadas pelo teste de Duncan $(\mathrm{p}<0,05)$.

Após a seleção dos inseticidas clorpirifós-etil e tebufenozide como os mais eficientes para o controle da lagarta-enroladeira, realizou-se um experimento de avaliação do efeito desses inseticidas em pomar comercial. O trabalho foi conduzido em pomar da cultivar Fuji de seis ha, com oito anos de idade, plantada no espaçamento de $1,8 \mathrm{~m} \times 4,5 \mathrm{~m}$, o qual foi dividido em três talhões de dois ha cada. Nos talhões, foram colocadas quatro armadilhas tipo delta, contendo septos de borracha com o feromônio sexual sintético de $B$. cranaodes (Unelius et al., 1996). O espaçamento entre as armadilhas foi de $25 \mathrm{~m}$ entre si, na altura de $1,8 \mathrm{~m}$ do solo. A partir de outubro de 1997, semanalmente, foi realizada a contagem do número de adultos capturados nas armadilhas. Os inseticidas clorpirifós-etil (Lorsban $480 \mathrm{CE}$ - $72 \mathrm{~g}$ de i.a./100 L) e tebufenozide (Mimic $240 \mathrm{SC}$ - 21,6 g de i.a./100 L) foram aplicados com auxílio de um turbo-atomizador tratorizado, num volume de $1.200 \mathrm{~L}$ de calda por ha, nos talhões correspondentes, deixando-se um talhão como testemunha. A aplicação dos inseticidas foi realizada nos dias 29/1 e 4/3/1998, após ter ocorrido um pico na captura de adultos na área-testemunha. $\mathrm{O}$ número médio de insetos capturados nas quatro armadilhas em cada talhão foi plotado em função do tempo, demonstrando a flutuação dos adultos nos talhões, e, conseqüentemente, o efeito dos inseticidas. $\mathrm{O}$ dano provocado pela lagarta-enroladeira foi avaliado, na colheita, em dez sacolas por talhão (com aproximadamente 100 frutos cada), nos dias 30/3 e 20/4/1998. Nestas datas, foram colhidos aproximadamente $70 \%$ e $30 \%$ dos frutos existentes na área experimental, respectivamente. $\mathrm{O}$ dano provocado pela praga nas diferentes áreas foi comparado pelo teste de Duncan $(\mathrm{p}<0,05)$. Além dos tratamentos do experimento, foi aplicado o inseticida fosmet (Imidan 50 PM, $100 \mathrm{~g}$ de i.a./100 L) em 23/10/1997, para o controle da mosca-das-frutas em toda a área experimental.

\section{RESULTADOS E DISCUSSÃO}

No experimento de laboratório, todos os inseticidas aplicados sobre lagartas recém-eclodidas provocaram $100 \%$ de mortalidade 24 horas após a infes- tação nas folhas tratadas. Não foi observada mortalidade de lagartas na testemunha.

Quando o experimento foi instalado com lagartas de 4ㅇ e 5o ínstar, os inseticidas fosmet, fenitrotiom e tebufenozide não provocaram mortalidade significativa aos 2 DAT, enquanto o clorpirifós-etil provocou mortalidade de $87,2 \%$, o triclorfom de $76,6 \%$ e os demais tratamentos proporcionaram um controle intermediário (Tabela 1). Aos 5 DAT, os inseticidas clorpirifós-etil, tebufenozide e triclorfom foram considerados eficientes no controle das lagartas de $40 \mathrm{e}$ 5o ínstar de B. cranaodes, proporcionando mortalidade superior a $80 \%$. A diferença na mortalidade das lagartas tratadas com tebufenozide dos 2 aos 5 DAT, deve-se ao modo de ação do inseticida, que é mais lento em relação aos produtos neurotóxicos (Hadialla et al., 1998). Os demais tratamentos não proporcionaram um controle satisfatório da praga (Tabela 1). Kovaleski (1994) obteve uma mortalidade final de $100 \%$ com os inseticidas fosmet e fenitrotiom, nas mesmas dosagens avaliadas neste trabalho. Entretanto, a infestação foi realizada após a aplicação dos inseticidas, ao contrário deste experimento, que permitiu ao inseto abrigar-se (enrolar) nas folhas antes da aplicação dos produtos, tornando, assim, mais difícil o contato com a calda de pulverização. Os inseticidas fosmet e fenitrotiom têm sido empregados no manejo de pragas da cultura da macieira no Brasil por um longo período de tempo (Orth et al., 1986), o que sugere a existência de populações de B. cranaodes resistentes aos inseticidas fosforados, podendo explicar a variação encontrada na mortalidade do inseto.

No experimento conduzido sobre plantas adultas no campo, o dano provocado pela lagarta-enroladeira nas plantas testemunhas foi significativamente superior ao das protegidas pelos inseticidas; não foram observadas diferenças entre os produtos aplicados (Tabela 1). O destaque verificado com clorpirifós-etil e tebufenozide quando aplicado sobre lagartas de 40 e 5o ínstar não foi confirmada em relação ao dano nos frutos (Tabela 1) porque a pulverização dos inseticidas por calendário (a cada 21 dias) atingiu, provavelmente, as diferentes fases de desenvolvimento do inseto, e o efeito repelente impediu a oviposição e o conseqüente estabelecimento da praga nas plantas de macieira. No entanto, a aplicação seqüencial 
dos produtos, em intervalos preestabelecidos, pode impedir a implementação do manejo integrado de pragas pelo emprego de inseticidas no momento em que o monitoramento do inseto indique a necessidade de tal intervenção. Os inseticidas fenitrotiom, fosmet e metidatiom, embora tenham apresentado baixo controle de lagartas grandes, quando aplicados a intervalos preestabelecidos no campo, protegeram os frutos contra $\mathrm{o}$ ataque do inseto. $\mathrm{O}$ mesmo efeito foi observado com o carbaril, mas o produto apresenta restrições por causa da ressurgência da população de ácaros fitófagos após o seu uso (Thistlewood \& Elving, 1992).

No experimento de validação dos inseticidas clorpirifós-etil e tebufenozide em pomar comercial, foi observado que a população de adultos mantevese baixa (máximo 2 adultos/armadilha/semana) até o dia 21 de janeiro, quando foi verificado o primeiro pico populacional da praga ( 9 adultos/armadilha/semana) na área experimental (Fig. 1). Após a aplicação dos inseticidas em 29/1/1998, observou-se uma redução na captura dos adultos nas armadilhas nas semanas seguintes. A segunda aplicação foi realizada após o pico populacional de 32 adultos/armadilha/semana ocorrido na área testemunha no dia 3/3/1998. Nesta avaliação, a população de adultos na área testemunha foi 32 e quatro vezes superior aos talhões tratados com clorpirifós-etil e tebufenozide, respectivamente (Fig. 1). A população de adultos observada na área tratada com clorpirifósetil manteve-se baixa até o final da colheita. Tal fato não ocorreu na área tratada com tebufenozide, e após a segunda aplicação, o número de adultos capturados semanalmente nas armadilhas foi praticamente igual ao observado na área testemunha (Fig. 1).

A elevada população de adultos capturada nas armadilhas com feromônio sexual na área tratada com o tebufenozide após a segunda aplicação, foi atribuída ao modo de ação do inseticida. Como o produto é específico para a fase de lagarta, pupas e adultos não são afetados no momento da aplicação, o que permite às fêmeas ovipositarem após o tratamento, e, conseqüentemente, dar continuidade ao crescimento da população dessa praga no pomar.

Em face da elevada produção de maçãs por unidade de área, os produtores não aceitam danos causados por insetos acima de $1 \%$ da produção. Nesta situação, no pomar comercial, somente o inseticida clorpirifós-etil proporcionou um controle satisfatório da praga (Tabela 2). Embora o tebufenozide tenha reduzido em $50 \%$ o dano quando comparado com a área testemunha, novas estratégias de emprego do inseticida devem ser avaliadas como a aplicação seqüencial visando controlar, além das lagartas presentes na área, os descendentes dos adultos que não foram atingidos numa única pulverização. Para que

TABELA 1. Número médio ( \pm EP) por planta, porcentagem de controle $(\% \mathrm{C})$ de lagartas do 40 ao 5o ínstar de Bonagota cranaodes e porcentagem de frutos danificados por lagartas, após a pulverização de inseticidas sobre plantas de macieira da cultivar Fuji, em campo. Vacaria, RS, 1997.

\begin{tabular}{|c|c|c|c|c|c|c|c|c|}
\hline \multirow{2}{*}{$\begin{array}{l}\text { Produto comercial } \\
\qquad(\mathrm{PC})\end{array}$} & \multirow{2}{*}{$\begin{array}{l}\text { Ingrediente } \\
\text { ativo (i.a.) }\end{array}$} & \multicolumn{2}{|c|}{ Dosagem $^{2}$} & \multicolumn{2}{|c|}{$2 \mathrm{DAT}^{3}$} & \multicolumn{2}{|c|}{$5 \mathrm{DAT}$} & \multirow{2}{*}{$\begin{array}{c}\text { Frutos } \\
\text { danificados } \\
(\%)\end{array}$} \\
\hline & & $\mathrm{PC}$ & i.a. & $\mathrm{N}$ & $\% \mathrm{C}$ & $\mathrm{N}$ & $\% \mathrm{C}$ & \\
\hline Dipterex 500 & Triclorfom & 300 & 150 & $1,1 \pm 0,27 d$ & 76,6 & $0,7 \pm 0,37 \mathrm{bc}$ & 80,6 & $3,03 \pm 0,93 a$ \\
\hline Imidan $50 \mathrm{PM}$ & Fosmet & 200 & 100 & $4,1 \pm 0,34 \mathrm{ab}$ & 12,8 & $2,6 \pm 0,40 \mathrm{a}$ & 27,7 & $1,96 \pm 0,65 a$ \\
\hline Lorsban $480 \mathrm{CE}$ & Clorpirifós-etil & 150 & 72 & $0,6 \pm 0,21 \mathrm{e}$ & 87,2 & $0,4 \underline{ \pm} 0,24 \mathrm{c}$ & 88,9 & $1,42 \pm 0,50 \mathrm{a}$ \\
\hline Mimic 240 SC & Tebufenozide & 90 & 21,6 & $3,7 \pm 0,32 \mathrm{ab}$ & 21,3 & $0,6 \pm 0,40 \mathrm{c}$ & 83,3 & $1,80 \pm 0,43 a$ \\
\hline Sevin $850 \mathrm{PM}$ & Carbaril & 180 & 153 & $2,1 \pm 0,18 \mathrm{c}$ & 55,3 & $1,6 \pm 0,24 b$ & 55,6 & $2,11 \pm 1,36 \mathrm{a}$ \\
\hline Sumithion $500 \mathrm{CE}$ & Fenitrotiom & 150 & 75 & $3,6 \pm 0,32 \mathrm{ab}$ & 23,4 & $2,8 \pm 0,49 a$ & 22,2 & $1,91 \pm 0,56 a$ \\
\hline Supracid $400 \mathrm{CE}$ & Metidatiom & 150 & 60 & $3,1 \pm 0,50 \mathrm{bc}$ & 34,0 & $2,2 \pm 0,37 \mathrm{a}$ & 38,9 & $1,96 \pm 0,79 a$ \\
\hline Testemunha & - & - & - & $4,7 \pm 0,27 \mathrm{a}$ & - & $3,6 \pm 0,58 \mathrm{a}$ & - & $8,61 \pm 2,43 b$ \\
\hline C.V. $(\%)$ & - & - & - & 30,3 & - & 39,4 & - & 56,9 \\
\hline
\end{tabular}

\footnotetext{
Médias seguidas por letras distintas diferem entre si pelo teste de Duncan $(\mathrm{P}<0,05)$.

2 Gramas ou $\mathrm{mL}$ por $100 \mathrm{~L}$ de água.

3 Dias após aplicação dos inseticidas.

4 Avaliado sobre plantas adultas.
} 


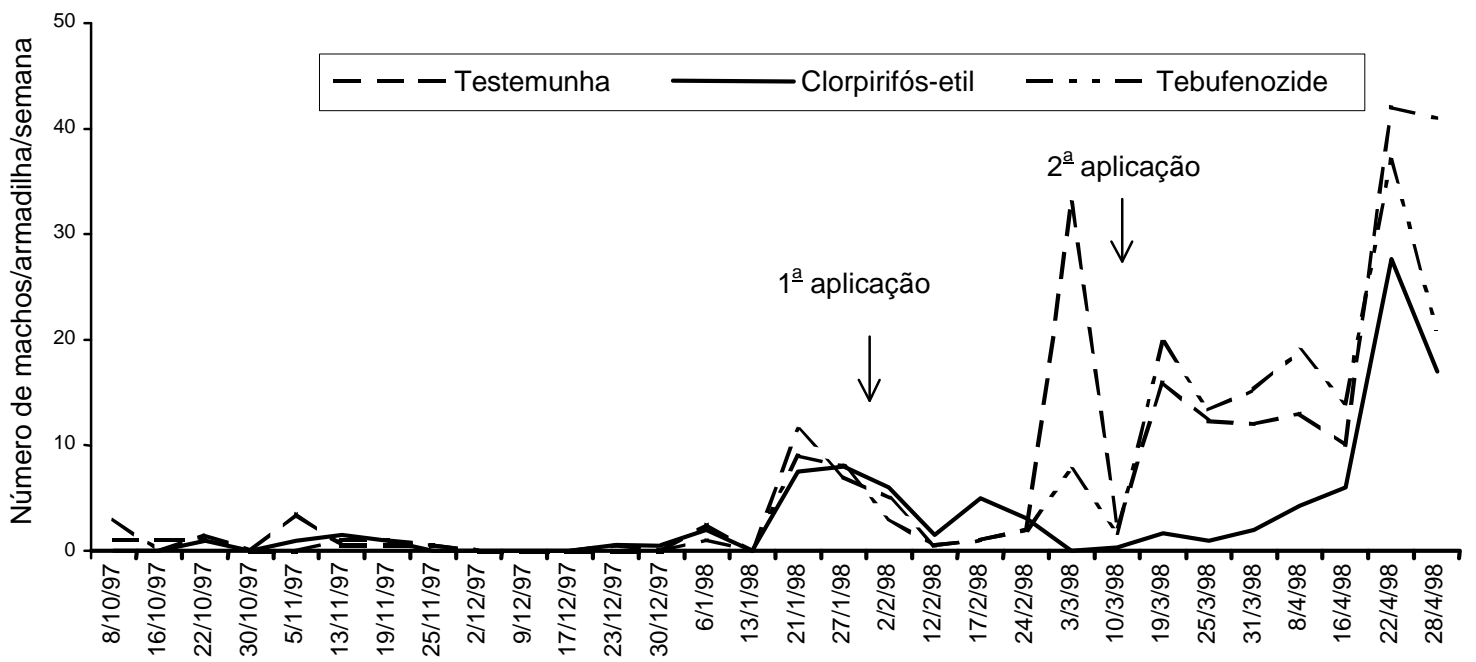

FIG. 1. Flutuação populacional de adultos de Bonagota cranaodes em armadilhas com feromônio sexual após a aplicação dos inseticidas clorpirifós-etil e tebufenozide. Vacaria, RS, 1997-98.

TABELA 2. Número de frutos colhidos (N) e porcentagem média de frutos danificados (FD) por lagartas de Bonagota cranaodes após o tratamento com os inseticidas clorpirifós-etil e tebufenozide em pomar comercial de macieira da cultivar Fuji. Vacaria, RS, 1997-981.

\begin{tabular}{|c|c|c|c|c|c|c|c|}
\hline \multirow{2}{*}{$\begin{array}{l}\text { Produto comercial } \\
\text { (PC) }\end{array}$} & \multirow{2}{*}{$\begin{array}{l}\text { Ingrediente } \\
\text { ativo (i.a.) }\end{array}$} & \multicolumn{2}{|c|}{ Dosagem $(\mathrm{mL} / 100 \mathrm{~L})$} & \multicolumn{2}{|c|}{$1^{\underline{a}}$ colheita } & \multicolumn{2}{|c|}{$2^{\mathrm{a}}$ colheita } \\
\hline & & i.a. & $\mathrm{PC}$ & $\mathrm{N}$ & $\mathrm{FD}(\%)$ & $\mathrm{N}$ & $\mathrm{FD}(\%)$ \\
\hline Lorsban $480 \mathrm{CE}$ & Clorpirifós-etil & 72 & 150 & 810 & $0,9 \pm 0,2 \mathrm{a}$ & 785 & $1,0 \pm 0,3 \mathrm{a}$ \\
\hline Mimic $240 \mathrm{SC}$ & Tebufenozide & 21,6 & 90 & 765 & $3,1 \pm 0,3 b$ & 815 & $8,2+0,5 b$ \\
\hline Testemunha & - & - & - & 800 & $6,6 \pm 0,8 \mathrm{c}$ & 796 & $17,2 \pm 1,8 \mathrm{c}$ \\
\hline
\end{tabular}

1 Médias $( \pm$ EP) seguidas por letras distintas diferem entre si pelo teste de Duncan $(\mathrm{p}<0,05)$.

esta tática possa ser empregada, ainda é necessário avaliar o período residual do inseticida e o momento mais indicado para o tratamento durante o pico populacional.

A especificidade do inseticida tebufenozide praticamente impede o emprego do produto em períodos de ocorrência conjunta de outras espécies, como a mosca-das-frutas. Por este motivo, outra estratégia de controle a ser avaliada é o emprego do inseticida no período de floração, visto que nesta época, pela presença das abelhas, não existe disponível outro grupo químico eficiente que possa ser empregado no controle da lagarta-enroladeira.

Neste trabalho, a decisão do momento de aplicação dos inseticidas foi tomada com base no incre- mento da captura de adultos nas armadilhas em relação à avaliação conduzida na semana anterior. Entretanto, como o inseto apresenta várias gerações durante o ciclo da cultura, o dano pode ser acumulado ao longo das gerações, dificultando o estabelecimento do nível de controle. Na área experimental, a captura de nove adultos/armadilha/semana em 27/1, representou um pequeno pico populacional quando comparado ao ocorrido em março (Fig. 1). Neste caso, o nível populacional observado em janeiro pode não justificar o tratamento na cultivar Gala, cuja colheita termina em fevereiro. Na cultivar Fuji, entretanto, colhida em abril, o dano resultante desta geração irá se somar com a de março, resultando em prejuízos acima dos tolerados comercialmente. Avalia- 
ções mais precisas em relação ao número de adultos capturados nas armadilhas com feromônio sexual e o dano causado pela lagarta-enroladeira ainda se fazem necessárias para avaliar e implementar o manejo das pragas na cultura da macieira.

\section{CONCLUSÕES}

1. Os inseticidas clorpirifós-etil, metidatiom, fosmet, triclorfom, tebufenozide, fenitrotiom e carbaril são eficientes no controle de lagartas recémeclodidas de Bonagota cranaodes.

2. O controle de lagartas de 4 o e 5o ínstar de $B$. cranaodes pode ser feito com os inseticidas clorpirifós-etil, triclorfom e tebufenozide.

3. Em pomares comerciais, o emprego de armadilhas Delta contendo o feromônio sexual sintético de $B$. cranaodes permite direcionar as aplicações de inseticidas e avaliar o efeito deles sobre a população da praga.

\section{AGRADECIMENTOS}

À Agropecuária Schio, por ceder os pomares de macieira para realização dos experimentos.

\section{REFERÊNCIAS}

ABBOTT, W.S. A method of computing the effectiveness of an insecticide. Journal of Economic Entomology, Lanham, v.18, n.1, p.265-267, 1925.

HADIALLA, T.S.; CARLSON, G.R.; LE, D. New insecticides with ecdysteroidal and juvenile hormone activity. Annual Review of Entomology, Palo Alto, v.43, p.545-569, 1998.
KOVALESKI, A. Eficiência dos inseticidas no controle da lagarta-enroladeira (Phtheocroa cranaodes) em condições de laboratório. Horti Sul, Pelotas, v.3, n.2, p.30-32, 1994.

KOVALESKI, A.; BOTTON, M.; EIRAS, A.E.; VILELA, E. Lagarta-enroladeira da macieira: bioecologia e controle. Bento Gonçalves : Embrapa-CNPUV, 1998. 22p. (Embrapa-CNPUV. Circular Técnica, 24).

LORENZATO, D. Ensaio laboratorial de controle da "traça-da-maçã" Phtheochroa cranaodes Meyrick, 1937 com Bacillus thuringiensis Berliner e inseticidas químicos. Agronomia Sulriograndense, Porto Alegre, v.20, n.1, p.157-163, 1984.

ORTH, A.I.; RIBEIRO, L.G.; REIS FILHO, W. Manejo de pragas. In: EMPRESA DE PESQUISA AGROPECUÁRIA DE SANTA CATARINA (Florianópolis, SC). Manual da cultura da macieira. Florianópolis, 1986. p.341-379.

PARRA, J.R.P.; EIRAS, A.E.; HADDAD, M.L.; VILELA, E.F.; KOVALESKI, A. Técnica de criação de Phtheochroa cranaodes Meyrick (Lepidoptera : Tortricidae) em dieta artificial. Revista Brasileira de Biologia, Rio de Janeiro, v.55, n.4, p.537-543, 1995.

THISTLEWOOD, H.M.A.; ELVING, D.C. Laboratory and field effects of chemical fruit thinners on tetranychid and predatory mites of apple. Journal of Economic Entomology, Lanham, v.85, n.2, p.477-485, 1992.

UNELIUS, C.R.; EIRAS, A.; WITZGALL, P.; BENGTSSON, M.M.; KOVALESKI, A.; VILELA, E.F.; KARLSON, A.K.B. Identification and synthesis of the sex pheromone of Phtheochroa cranaodes Meyrick (Lepidoptera : Tortricidae). Tetrahedron Letters, Oxford, v.37, n.9, p.1505-1508, 1996. 